\title{
Confusions in the Anticommons
}

\author{
Ronald F. King ${ }^{1}$, Ivan Major ${ }^{2} \&$ Cosmin Gabriel Marian ${ }^{3}$ \\ ${ }^{1}$ Department of Political Science, San Diego State University, California, USA \\ ${ }^{2}$ Institute of Economics, CERS, Hungarian Academy of Sciences and Budapest University of Technology and \\ Economics, Hungary \\ ${ }^{3}$ Department of Political Science, Babes-Bolyai University, Cluj-Napoca, Romania \\ Correspondence: Ronald F. King, Department of Political Science, Nasatir Hall, San Diego State University, San \\ Diego, CA, 92182-4427, USA. Tel: 1-619-594-1094. E-mail: rking@mail.sdsu.edu
}

Received: March 5, 2016 Accepted: June 11, 2016 Online Published: August 30, 2016

doi:10.5539/jpl.v9n7p64 URL: http://dx.doi.org/10.5539/jpl.v9n7p64

\begin{abstract}
Tragedy of the anticommons is the logical reciprocal to the better-known tragedy of the commons. It is generally characterized as a legal regime in which multiple owners hold rights of exclusion over a resource in demand. The resource cannot be put into use without a bundling of approvals from the various separate owners, yet bundling entails serious bargaining complications resulting in systematic Pareto underutilization. Nevertheless, we argue, the anticommons concept often has been employed without consistency and appropriate precision. Illustrations come primarily from the writings of Michael Heller, whose oft-cited work has been central to the anticommons literature. This paper presents a simple version of the formal anticommons model and demonstrates that relevant applications can be constructed with uniformity and analytic rigor.
\end{abstract}

Keywords: anticommons, rational tragedies, segmented property rights, non-cooperative games, bundling failure

\section{Introduction}

Tragedy of the anticommons has been the subject for dozens of academic papers, both analytic explorations and empirical applications. It is even the title of a punk rock song (Max Levine, 2010). According to Michael Heller, the scholar most responsible for developing and popularizing the term, anticommons is defined as "a property regime in which multiple owners hold effective rights of exclusion in a scarce resource" (1998, p. 668). The resource cannot be put into use without a bundling of approvals from the various separate owners, yet bundling entails serious bargaining complications resulting in systematic underutilization. Tragedy of the anticommons is conventionally contrasted with the more familiar tragedy of the commons, in which multiple owners of a scarce resource hold effective rights of use but not of exclusion, resulting in systematic over-utilization.

Nevertheless, 'anticommons' has not always been applied with appropriate precision. Our goal in this paper is to save the concept, not to bury it. First, the notion of property, allegedly essential for the identification of legal regimes where multiple actors possess exclusion rights, is often stretched far beyond ordinary meaning. Although introduced haphazardly, this conceptual stretching, we argue, is not inherently implausible. Anticommons is more reasonably defined with minimum reference to legal property, as including all potential bundling situations comprised by separate, complementary, and necessary inputs.

Second, anticommons illustrations in many cases have not been constructed with adequate attention to the strategic calculations of the actors and the logic through which inefficiency occurs. Far too often, it refers broadly to any occasion of multiple-actor bargaining failure, with little or no reference to the underlying causes. Whereas the first expansion of the anticommons concept can be justified, this second expansion cannot. While bundling of necessary permissions is regularly a problem in negotiations, there already exists sufficient language to describe most ordinary types of bargaining failure. Anticommons tragedy contributes to the law-and-economics literature on externalities by its identification of one particular game-theoretic situation, in which maximizing players achieve Nash equilibrium at less than Pareto optimal accomplishments. There are ample anticommons illustrations in the real world without having to muddle the discussion with other, vague and misleading characterizations. 
The paper proceeds in four sections. The first introduces a simple version of the anticommons model, demonstrating its inherent logical structure. The second discusses confusions over the meaning of anticommons property. The third discusses confusions over the causes of anticommons inefficiency, formulated in terms of the Coase theorem. Evidence for these sections comes primarily from a close examination of the writings of Michael Heller, whose oft-cited work has been central to the entire anticommons literature. The final section suggests a number of relevant applications based upon a more consistent and rigorously specified anticommons concept.

\section{On Anticommons}

Commons and anticommons problems both exist due to rights fragmentation in situations of collective ownership or control. In the tragedy of the commons, each of the multiple owners of a property has unconstrained privileges of use without the means to constrain the use privileges of others. By contrast, in the tragedy of the anticommons, each of the multiple owners of a property has unconstrained rights of exclusion over the use privileges of others without the means to insure use privileges for themselves or their designated agents. In a sense, the commons situation occurs when there are too few effective property rights barriers; the anticommons situation occurs when there are too many effective property rights barriers. Alternatively, the commons situation can be conceptualized as a problem of separate and supplementary resource rights, whereas anticommons is a problem of separate yet complementary resource rights. In both, there is an optimal result to be discovered through mutual cooperation; in both, any actor who unilaterally pursues cooperation will suffer a penalty. Therefore, as long as the actors remain separate, none will fully cooperate. Rationally, all will calculate an individually maximizing position, and the combined outcome will remain inefficient despite complete actor awareness and their desire to achieve an optimzing result.

In anticommons, each of the owners has the unconstrained ability, as in cases of joint tenancy, to block or restrict supply of a mutually controlled property, whether directly through prohibitions and conditions upon the quantity made available or indirectly through a price imposed for use or sale. Nevertheless, none of them can dictate the value generated by that property, for that is a consequence of the sum of their individual decisions. At the core of the anticommons problem, therefore, is the need to assemble or 'bundle' a set of necessary permissions. Each of the autonomous owners individually bears her own costs from granting use permission. Each owner is fully entitled to set her own limits upon permission, independent of all others. Only as a collective bundle, however, do these permissions allow the property to function; only as the consequence of bundled agreements can the property generate benefits to be apportioned.

The complication is that the benefits from successful bundling sit as a positive externality resulting from the permissions given. Each owner can realize only a portion of the anticipated external gain, and need not place any value on the portion secured by others. There is thus incentive for strategic play over the distribution of rewards. The ultimate power for each player is her individual right to veto any proposed utilization of the common property. Yet such action denies benefits to all, including the player imposing the veto. Anticommons thus poses interconnected problems of permission-assembly and reward-allocation, both of which must be solved jointly in order for the property to be productively employed. The impending tragedy is caused by the fact that, when the players do not fully internalize the penalties imposed from strategically enforcing their rights to exclude, potential value will remain unrealized. The combination of their separate maximizing behaviors causes net prices to be higher than optimal and thus returns to be lower, both in the aggregate and also for the players individually. (Reciprocally in the commons situation, the combination of maximizing behaviors causes net quantities to be higher than optimal and thus returns to be lower.) Importantly, tragedy prevails even under conditions of rational understanding and perfect information.

The problem can be demonstrated formally by means of a simple, non-cooperative game theoretic model, developed initially by Buchanan and Yoon (2000) and advanced subsequently (Schultz, Parisi \& Depoorter, 2002; Parisi, Schulz \& Depoorter, 2004; Parisi, Schulz \& Depoorter, 2005). Imagine first a market transaction between bi-lateral monopolies. The value received by the seller equals the market price times the quantity of goods sold at this price:

$$
V=P^{*} Q(P)
$$

For simplicity of calculation, we assume zero fixed and marginal costs. The buyer has the following demand curve:

$$
Q=1-P
$$

Again for simplicity, we assume a decrease of one unit of quantity for each unit of price.

The seller rationally will calculate the first-order condition of the rent maximization: 


$$
\frac{d V(P)}{d P}=\frac{d[(1-P) P]}{d P}=1-2 P=0
$$

Solving the equations for price, quantity, and value produced:

$$
P=1 / 2 ; \quad Q=1 / 2 ; \quad V=1 / 4
$$

The result is a unique and efficient equilibrium.

Next, we introduce a critical complication. Assume that there are two or more actors who jointly must agree in order to sell the product in question. Note that this is not the usual postulate of multiple sellers in competition, each of whom seeks the highest return for her own, solely possessed good. Rather, in the anticommons the separated owners jointly control the sale of the product.

The quantity demanded and the total value now depend on the sum of the prices each owner individually charges. For now, we posit only two owners of the property.

$$
\begin{gathered}
Q=1-P_{1}-P_{2} \\
V\left(P_{1}+P_{2}\right) Q=\left(P_{1}+P_{2}\right)\left(1-P_{1}-P_{2}\right)
\end{gathered}
$$

The return to Owner 1 is:

$$
P_{1} Q=P_{1}\left(1-P_{1}-P_{2}\right)
$$

while the return to Owner 2 is:

$$
P_{2} Q=P_{2}\left(1-P_{1}-P_{2}\right)
$$

The difficulty for Owner 1 is that she cannot directly control the value received. She can dictate $P_{1}$ and its partial effect upon $Q$, but the total $Q$ is also affected by the autonomous price behavior of Owner 2. Similarly for Owner 2, he can dictate $P_{2}$ and its partial effect upon $Q$, but the total $Q$ is also affected by the autonomous price behavior of Owner 1. Each of the owners thus faces risk because of the independent but associated decision-making capacity of the other. Both owners, moreover, have strong reason to suspect that the other will not select a price that, when summed, will together equal the maximizing $P=1 / 2$.

One can imagine a simple two-person Chicken Game (Fennell, 2004; 2011). Mutual agreement would have permitted sale at the efficient price and quantity, but it will not be achieved because of dominating rational incentives to play otherwise. Each player knows that, for any possible $P^{*} Q$ combination, she can generate a higher personal return by selecting a higher relative price given that she can induce other player to select a lower one. This is enforced by the threat not to sell at all, leaving the partner with no prospective return. Asymmetric holdup can be used by an aggressive veto-player to extract a higher rental payment or impose desired concessions from those predisposed toward cooperation and impatient for the project to proceed. The great risk, however, is that both players might simultaneously adopt aggressive strategies. It is always in their interest to pretend high and intractable reservation prices, backed by the threat that they would prefer no agreement to any further concessions. It is then likely that the separate sellers will regard each other with mutual antagonism, uncertainty, and distrust. If they remain firm and refuse to yield, the sum of their prices will be considerably too high. In the extreme, the buyer abandons the hope of purchase, resulting in complete bundling failure.

Yet this formulation is not complete. A further and more plausible alternative exists for actors who understand their self-interest in insuring a positive net payoff while simultaneously pursuing the highest possible gain relative to others in the same situation, and who are clever or experienced enough to know that the other actors will be thinking similarly. In the anticommons, both Owner 1 and Owner 2 set their prices autonomously from the other, intending to optimize anticipated returns while recognizing that the other will be doing the same. Cournot-Nash solutions entail that the "best response" for any player occurs when she has selected the strategy that yields a maximizing payoff regardless of the strategy selected by the other player. Equilibrium prevails when neither player has incentive unilaterally to shift best response strategy.

If fully rational, Owner 1 will adopt the first-order condition of rent maximization in which the first derivative of her payoff by her price $\left(d \mathrm{~V}_{1} / d \mathrm{P}_{1}\right)$, contingent upon the price charged by the other player, is set at zero since she wishes it to be invariant regardless of what the other player chooses to do. Owner 2 will act similarly.

Thus, for Owner 1:

$$
\frac{d V_{1}}{d P_{1}}=\frac{d\left[\left(1-P_{1}-P_{2}\right) P_{1}\right]}{d P_{1}}=1-2 P_{1}-P_{2}=0 \quad \mathrm{P}_{1}=1 / 3
$$


and for Owner 2:

$$
\frac{d V_{2}}{d P_{2}}=\frac{d\left[\left(1-P_{1}-P_{2}\right) P_{2}\right]}{d P_{2}}=1-P_{1}-2 P_{2}=0 \quad \mathrm{P}_{2}=1 / 3
$$

(The result for the two owners is symmetrical merely because they were constructed identically by the simplifying assumption that all marginal costs equal to zero.) Solving the equations for the anticommons price, quantity and value produces:

$$
P_{a}=P_{1}+P_{2}=2 / 3 ; \quad Q_{a}=1 / 3 ; \quad V_{a}=2 / 9 .
$$

It thus has been shown that rational and perfectly informed maximizing behavior in the strategic anticommons, with multiple but separated owners of a single property, yields a higher than optimal net price and a lower than optimal net quantity. There is a conscious equilibrium result from anticommons non-cooperative game calculations, but it is systematically tragic. The outcome generates lower net value, in the aggregate and for each of the separated owners, compared to an alternative property regime in which they had agreed to act cooperatively as a unified cartel. Sale of the joint property does occur, but at a suboptimal level.

$$
V_{1}+V_{2}=V_{a}<V
$$

The anticommons model exists in multiple variants, all of which can be shown to be virtually identical in effect. For instance, it does not matter for the above illustration whether play concerns the sale of the goods produced by a jointly controlled property or sale of the joint property, itself. The above illustration was constructed with the owners playing strategically over the price to be charged; no difference occurs if they play instead over restrictions on the quantity to be supplied. The above illustration has an outsider buyer interested in purchasing a collectively controlled product with two independent owners; no difference occurs if instead the potential buyer is one of the owners seeking to obtain unified control. The finding here was generated from only two separated players; the calculated suboptimality actually increases monotonically with the number of players to the game:

$$
\sum_{i=1}^{n} P_{i}=\frac{n}{n+1} ; \quad Q=\frac{1}{n+1} ; \quad V_{a}=\frac{n}{(n+1)^{2}}
$$

The finding does not depend on perfect strategic rationality; in fact the degree of anticipated suboptimality also increases to the extent that any player unilaterally deviates from her ideal calculated position.

There exists a prospective social benefit that would accrue once autonomous actors voluntarily cooperate in a joint venture, together selling their co-owned product to the willing buyer. Yet that benefit will not be entirely realized. Cooperation can fail because of bargaining collapse, always a potential occurrence when one or more veto-players have the incentive to play strategic holdup. Yet, importantly, inefficient underutilization is likely even when all the separated actors unanimously grant permission and sale is a success, as a consequence of them autonomously selecting the best available strategic position while recognizing that the others are calculating similarly. Behavior that is individually rational and maximizing thus results in outcomes that are collectively perverse and systematically suboptimal. It is a logical consequence when the owners of a scarce resource play against each other as well as against the player who wishes to purchase some share of that resource.

The implication is that the anticommons tragedy is deeply inherent and widely pervasive whenever separated owners possess rights of exclusion over a product or activity requiring complementary approvals. A more preferable outcome is visible, in which bundling is achieved and Pareto efficient values are realized, but it rationally will not be found given the initial position of property fragmentation. There should be many relevant examples. Think of Shakespeare's King Lear who fragmented his authority and announced his dependence upon voluntary contributions from the separate households of his daughters; had he understood the anticommons dilemma, he would never have claimed that he was more sinned against than sinning.

\section{On Anticommons Property}

Whereas the theoretical anticommons model seems clear and unambiguous, the practical literature is far less so. The above model was based on separated owners of a collective property whose strategic behavior leads systematically to Pareto inefficient underutilization. The applied literature, we will discover, is often vague regarding both the entailed notion of property and the behavioral logic that produces inefficiency. Conceptual confusions have led to imprecise applications, reducing significance and distorting meaning.

The notion of property has changed dramatically since Blackstone (1765-1769) and his famous assertion that 
property entails the "sole and despotic dominion which one man claims and exercises over the external things of the world, in total exclusion of the right of any other individual in the universe." Property has become defined less by dominion over possessions and more as a complex set of legal relationships among interdependent humans (Hohfeld, 1919). Although not without critics, the dominant paradigm today is that property is comprised by a complex grouping of rights. In the classic version by Honore (1961), the standard list includes the rights to possess, use, manage, receive income, sell or consume, transmit, and bequeath. No single item in the group is individually necessary. Not all items need to be equally strong. It is possible for separate actors to control different items within the set. Property ownership thus becomes very flexible, admitting considerable variation across time, legal systems, and type of asset considered.

The anticommons dilemma is in part rooted in the fluidity of property theory (Heller, 1999). The existence of multiple separated owners - each capable of imposing restrictions on use, none capable of exercising the privilege of use - entails a compound construction quite distant from Blackstone. This fluidity, especially as seen in the work of Michael Heller, has facilitated a wide range of anticommons applications. As a consequence, however, there exists the potential for confusion regarding which particular arrangements of fragmented property legitimately should be identified as falling within the anticommons category and which should be excluded. At a certain point of conceptual stretching, it becomes preferable to abandon a strained and overburdened condition in this case the centrality of legal property rights to the definition of anticommons - and instead to venture in a different, more consistent direction.

The analytic story featured in much of the literature focuses on the entitled owners of a collective property who need to consent simultaneously in order to sell the product(s) generated. Imagine, for instance, a garage where individuals who wish to park their cars must obtain one permission ticket from Owner $i$ at Price $i$ and a second from Owner $j$ at Price $j$. In the anticommons, the sum price charged will be higher and the number of cars parked will be lower than optimal. Or, for instance, imagine grown children jointly inheriting the family farm, each autonomously deciding whether and at what price to lease the land to a neighboring farmer; the neighbor negotiates separately with each of the children and must bundle their permissions in order to obtain the lease. There are related real-world illustrations, often concerning partible inheritance. For example, according to Heller, the U.S. government in the late $19^{\text {th }}$ Century broke up many Native American tribal reservations, allotting the land to individual families. As a result of inheritance, for one reservation in North and South Dakota, the average 40-acre tract has 196 different owners and the average owner has property interest in 14 tracts (Heller, 2008, pp. 108-109; 125-129). A bundling outcome, even if achieved, would be enormously inefficient compared to the situation of bi-lateral monopoly.

Heller's examples, however, extend to other types of property situations. In his 'spatial anticommons', each of the separated owners has exclusion rights over merely a portion of the larger property. Imagine a forest divided spatially into a multitude of small lots, each of which is owned by a different individual, none of which is economically viable by itself. As above, there is an agent who seeks to lease all of the lots, anticipating a positive return above cost. Again there is a bundling problem, but with two significant differences. First, in the farm inheritance example, the separated owners each possess segmented ownership rights over the whole. In this forest example, the separated owners possess full ownership rights over a part. Each can legally use, rent, transfer, bequeath, etc. her portion of the forest, although these rights have no real value in themselves as the portion is too small to be used successfully. Second, whereas the farm property actually exists, the unified forest remains in potential and will only come into reality upon successful bundling of the parts. Put differently, the unified family farm is constituted legally by the composite of the separate owners and their property rights to exclude but not use. By contrast, the unified forest is constituted only in anticipation as the composite of separate but relatively useless forest segments, each with an owner exercising full property rights.

The two stories are identical in terms of the rational calculations of the anticommons formal model. Both require coordination in order to establish effective property use; both award refusal rights to each autonomous owner, providing incentive for strategic play. Nevertheless, the underlying notion of property ownership is quite different. In the logic of spatial anticommons, one is asked to consider the individual owners of the forest segments as if they were simultaneously owners of some hypothetical, unified forest property over which they have autonomous rights of exclusion. The leap is easiest if the forest is conventionally thought of as a single entity or if it had once existed as a single entity that later was divided into differentiated, small ownership segments. An example from Heller of the former is the New York Times' effort to purchase the land of a New York City block (2008, pp. 109-111); an example of the latter is komunalka apartments in post-communist Russia in which each owner was given legal title exclusively to her room within a subdivided larger apartment (2008, pp. 159-161). Heller often writes as if it is typically the case that anticommons property fragments are 
created by excess subdivision. "Privatization," he states, "can overshoot. Sometimes we create too many separate owners of a single resource" (2008, p. 2).

Yet Heller also provides examples of spatial anticommons where there was no previous unity. Even further, there are examples where the separated owners most probably do not even recognize that they possess a segment of a potential whole - until someone proposes a price for the permissions to bundle. The most striking of these concerns the proposed construction of new airport runways (2008, pp. 8-9; 2013, pp. 6-7). Homeowners in the area have full property rights to their lands and the structures built upon them. They are apparently satisfied with their properties, evidenced by the fact that they have not put them up for sale. They would not ordinarily consider themselves partial 'owners' of some hypothetical collective property consisting of all lands that must necessarily be bundled if anyone ever proposes to build a new airport runway. Anticommons relevance, however, is said to exist once an airport authority seeks to purchase all the separate parcels, giving to each homeowner exclusion rights over the creation of a new, joint property and thus empowering them in subsequent bargaining relationships.

By analogy, Heller further extends the notion of spatial anticommons to 'ownership' over segments of the telecommunications bandwidth. The U.S. Federal Communications Commission grants licenses that award the holder exclusive rights to broadcast within a specified domain. "Although this isn't ownership in the everyday sense," he writes (2008, p. 82), "we can translate existing license regimes more or less into familiar ownership categories." Given the inefficient use of U.S. bandwidth, with much of the available range underutilized, and given the ability of current license-holders to deny use and prevent reallocation, Heller argues that there is sufficient similarity for the language of anticommons to apply.

Next, Heller makes an explicit distinction between situations of spatial anticommons, where the 'owners' of a potentially bundled new property are differentiated by territory, and situations of legal anticommons, where the 'owners' are instead differentiated by function. In spatial anticommons, the owners control a physical segment that they have the right to withhold. In legal anticommons, the owners have control over necessary permissions (1998, p. 671). For example, storefronts in post-communist Moscow remained empty, says Heller, because the legal rights to lease, use, sell, occupy, etc. had been assigned to different, overlapping actors and could not be successfully reassembled. A similar logic is applied to intellectual rather than physical property. Documentary films allegedly are deterred because of the need to assemble the many required copyrights (2008, pp. 9-13). New pharmaceuticals are not developed because of the failure to assemble complementary patent permissions (2008, pp. 49-78).

Implicit here is another considerable extension for the concept of property. A copyright holder would certainly claim to have property over her song or film clip, but would not ordinarily think herself as a partial 'owner' of the unified set of copyrights that jointly are necessary components that need to be assembled for a yet-to-be produced documentary. A patent holder would claim to have property over his invention, but would not ordinarily think himself as a partial owner over the unified set of components necessary for some yet-to-be developed new drug. Anticommons relevance, Heller asserts, comes once a product developer determines that the various components are complementary requirements for a new unity to come into existence, thus giving to the separated rights-holders the power to refuse permission for use. He does not appear concerned by conceptual stretching to include "property rights in potential future products" (Heller \& Eisenberg, 1998, pp. 699). One might reply that he instead is referring to ownership of the various inputs necessary for the construction of some potential product anticipated to generate positive returns in the future, recognizing that the imagined but not yet created future product might well be exploited by some other actor. Heller's leap is considerable, but it is needed to include these important applications within his initial compass.

In Heller's usage, property assignment based on the right of exclusion is taken quite far. Effective exclusion can be either legal or illegal (1998, p. 640). Use permissions can be granted through enforceable contracts but they "need not be formally granted .. . for anticommons property to emerge" (1998, p. 669), as in the case of Moscow street kiosks and their informal protection agreements with the local mafia. Presumably, the power of the mafia, as an organization with the raw ability to prevent or permit kiosk creation, gives it pseudo-property rights with regard to the kiosks.

Similarly, the anticommons ownership concept is applied to non-economic as well as economic agents, including public sector decision-makers with the power to refuse consent or impose restrictions. According to Heller, "the idea extends to fragmented decision-makers more generally. Resource use often depends on the outcome of some regulatory process. If the regulatory drama involves too many uncoordinated actors - neighborhood and advocacy groups; local, state, and federal legislators; agencies and courts - the sheer multiplicity of players may 
block use of the underlying resource" $(2013$, p. 12). In the "regulatory anticommons," he writes elsewhere, projects must negotiate through the thicket of necessary approvals, diverting energies from productive utilization (2008, pp. 103-104). For instance, the "multi-layered gauntlet" of American land-use approval involves "environmental impact reviews, architectural review boards, subdivision regulations, historic preservation districts, landmark commissions, building permit requirements, rent controls," all of which can restrict development (2008, p. 132). Apparently, in Heller's formulation, the regulatory power to withhold approval grants to public institutions a form of partial property ownership over the land-use project.

Imagine that John and Mary have been dating for quite some time. John proposes marriage and their friends all agree that it would be a perfect match. Yet Mary rejects the proposal because she does not sufficiently love John or possibly because she failed to negotiate an acceptable distribution in the pre-nuptial contract. According to the framework offered by Heller, Mary is one among the separated pseudo-owners of a potential property that can be termed the John-Mary marriage alliance and she has refused permission for necessary bundling, resulting in anticommons underutilization. Or possibly Mary would have agreed had her father not opposed the match. In Heller's anticommons framework, the father is also among the property owners in the potential marriage, who holds rights of exclusion by virtue of his informal rather than formal powers to refuse bundling. Moreover, there are bureaucratic strictures - forms, fees, and regulations, often from different agencies - that must be satisfied in order for the marriage to take place. John might not yet be officially divorced from his former wife. Together they might not have enough money to pay for the license. In Heller's framework, the relevant government agencies are also property owners in the potential marriage property because they hold rights of exclusion due to their regulatory standing.

In fact, it is difficult to imagine a decision-making situation that does not entail permission bundling of one sort or another. By implication, the notion of property threatens to become expanded almost without limit. While conceptual fluidity is important, there reaches a point where one must wonder whether incorporating 'property' into the core definition of anticommons, as Heller contends, contributes anything useful at all.

There is an important family resemblance across the various applications of the anticommons concept. They all involve multiple, independent actors who control complementary inputs that collectively are necessary in order to utilize a resource or generate a product or make a decision deemed to have positive social value. If so, there is no apparent necessity to insert the concept of legal property as a critical element into this specification. Just the opposite, reliance upon 'property' within the definition of anticommons leads to considerable imprecision, as evidenced by the extent of conceptual stretching from Heller. The notion of separate, necessary yet complementary inputs is fully sufficient, more precise, and it highlights the logical preconditions to the anticommons problem, consistent with the non-cooperative game model presented above. The enormous elasticity of Heller's use of property, extended to facilitate virtually any situation threatening bundling failure, casts the scope of anticommons so ambiguously as to lose analytic specificity. Our recommendation, therefore, is to minimize reliance upon property rights, to delete the concept from the anticommons definition, and instead to ground anticommons situations upon the elements requisite to initiate the strategic calculations represented in the underlying model.

\section{On Anticommons and the Logic of Tragedy}

The previous section addressed confusions in the literature regarding the preconditions that establish the anticommons situation. This section will address confusions regarding the logic by which tragic anticommons suboptimality occurs. In the previous section, we accommodated a wide range of alleged anticommons applications by shifting focus from vague property ownership to a more precise formulation based on multiple, necessary yet complementary inputs. In this section, we will impose restrictions on the legitimate use of anticommons. There already exist adequate words for most typical occasions of multi-actor bundling failure. Anticommons therefore should be limited only to those cases where, as in the formal model, the combined maximizing behavior of non-cooperative strategic actors nevertheless leads to Pareto inefficiency, thereby generating a rational tragedy reciprocal in construction to the well-known tragedy of the commons. Anticommons thus will occupy a rigorous domain that is both theoretically unique and empirically relevant. According to de Saussure's famous maxim, concepts are often understood by what they are not (1959, p. 117).

Of the empirical applications of anticommons, the most extensive concerns intellectual property rights, especially pharmaceutical and other biotechnology patents in the United States. The guarantee of exclusive rights over a product or process for a period of time creates an incentive to undertake costly R\&D, thus promoting innovation. Yet the multiplication of concurrent patent fragments conversely can serve as a barrier to innovation; the need to identify, obtain, and assemble a number of requisite approvals can cause important projects to be 
delayed, reformulated, or even abandoned. We shall briefly summarize the debate, and then focus on the motivations that underlie the alleged problem.

Michael Heller foresees danger from a number of directions (Heller \& Eisenberg, 1998). First, the proliferation of patents held by different owners produces complex "patent thickets' (Shapiro, 2001) comprised of multiple, overlapping, yet collectively necessary rights. It is costly, especially for small and start-up firms, to determine the approvals necessary and to secure them. Sometimes a patent-holder will arbitrarily refuse permission or impose a prohibitively high cost for a license. There exist lurking in the industry "patent trolls" who buy up seemingly worthless patents in the hope that some might be infringed upon and they can garner rents through litigation or the threat of litigation. In response to this complexity, firms aggressively have been expanding their own patent portfolios, "stacking licenses" (Ziedonis, 2004) in order to safeguard their investments and collect valued products for trade. Further, the situation is compounded by the long delays between filing and receiving biotechnology patents, creating uncertainty about the scope of the rights that ultimately might be bundled. Uncertainty is exacerbated by the existence of reach-through license agreements which give the upstream patent owners continuing rights to share in any returns from downstream products created by the licensed use of their component inputs. For empirical support, anticommons analysts tend to highlight dramatic examples in which difficulties in assembling a large number of necessary approvals deterred a useful biomedical project or in which an intransigent actor refused to grant critical permissions for use (Heller, 2008, pp. 50-59; Maurer, 2006; Park, 2011).

Critics reply that there is no actual incentive for extreme bargaining delays since patents gain economic value only when they are licensed and used (Kitch, 2003; Epstein \& Kuhlik, 2004). Most developers should be excited to negotiate necessary permissions, for otherwise costs cannot be recouped and profits cannot be made. Moreover, approvals sometimes have been granted without charge for altruistic reasons. In other cases, an affected research project has innovated around the blockage or simply adopted the technology without license. Surveys of leading biotechnology researchers and managers, including those sponsored by the National Academy of Sciences and the American Association for the Advancement of Science, found that virtually no one reported worthwhile projects abandoned or precluded by the need to obtain third-party patents; only a very small percentage reported any form of modification or delay (Walsh, Arora, \& Cohen, 2003; Walsh, Cho, \& Cohen, 2005; Hansen, Brewster, Asher \& Kisielewski, 2006). By contrast, the few econometric studies of intellectual property rights report modest but statistically significant negative patent effects (Murray \& Stern, 2007; Yuan, 2009).

The debate has been intense, with practical implications regarding the possible need to modify existing patent regulations to better achieve the public interest. However the debate has not been especially grounded theoretically. The critical question is, why should multiple actors with exclusion rights generate an outcome that is socially tragic, preventing useful biotechnology products from being developed in a timely and cost-effective manner. The answer most often given rests upon the Coase theorem, among the most important propositions of contemporary political-economics (Coase, 1960; 1988). Under ideal conditions absent any transaction costs, market exchanges regarding an initially misallocated externality will always achieve the efficient economic outcome regardless of the initial division of endowments.

Heller explicitly links his analysis of anticommons to the Coase theorem. "In theory," he writes, "in a world of costless transactions, people could always avoid commons or anticommons tragedies by trading their rights" (Heller \& Eisenberg, 1998, p. 698; also Heller, 1998, p. 673; Heller, 1999, p. 201; Heller, 2008, p. 46; Heller, 2013, p. 24). Allegedly, if people had perfect information, were perfectly rational, and could trade without encumbrance or constraints, they would escape all potential anticommons complexities, freely assembling fragmented property and putting resources to their highest-value use. In practice, Heller emphasizes, these conditions are never met. He lists three reasons why anticommons situations with multiple owners possessing exclusion rights over a scarce resource, especially biomedical anticommons, should deviate from the efficient result (Heller \& Eisenberg, 1998, pp. 700-701).

First, according to Heller, transaction costs should be particularly high because of the need to secure assembly of the many necessary patent inputs. The variety of institutions and situations impedes the development of standard agreements, forcing case-by-case negotiations. Second, actors have heterogeneous institutional agendas and interests that should complicate successful bargaining. Private firms, for example, might well prefer maintaining a lucrative product monopoly that rewards shareholders while government agencies would instead promote widespread availability at reasonable prices. Third, cognitive biases might thwart socially maximizing agreements. People commonly exaggerate the value of their own contributions to a project relative to the contributions from others. Each patent owner will tend to overestimate the probability that his patent will be 
critical, leading to bargaining impasse. Psychologically, people are less likely to assess accurately and take proper account of opportunity losses from gains unrealized as opposed to actual losses from resources already in possession. If so, there might be less motivation to pursue the bargaining process in cases of anticommons underutilization, as compared to cases of commons overutilization and depletion.

In essence, Heller and the scholars who follow his lead merely are claiming that, in situations of multiple complementary inputs, the obstacles to resource-maximizing negotiations are often especially high, resulting in harmful deviations from efficient allocation. The critics merely are replying that the obstacles are not distressingly severe. The debate is empirically interesting and policy relevant. Yet it is essential to recognize that both sides agree entirely regarding the theoretical formulation of the anticommons problem. The only issue is whether the actual fetters to input bundling, as fully recognized by Coase, cause or do not cause very costly deviations from the market-efficient bargains that would emerge, as hypothesized by Coase, under ideal negotiating conditions. We argue that this theoretical formulation is quite incorrect.

Heller is wrong when he asserts that anticommons tragedy would not exist in a world of rational actors bargaining freely and costlessly. In the non-cooperative game model of anticommons presented above, there is perfect information, perfect rationality, a clear delineation of property rights, and zero transaction costs. Nevertheless, the outcome is suboptimal and inefficient. The very object of the model is to show the systematic nature of the anticommons tragedy. Its occurrence is not the accidental product of transaction costs, bargaining distortions, institutional differences, psychological biases, or other constraints upon bundling. Rather, it is inherent to any game comprised from autonomous actors controlling complementary inputs, where separate but bundled consent is necessary to permit use and achieve an external gain. Tragedy occurs because the owners rationally calculate strategic maximizing positions, playing against each other as well as the actor who seeks to purchase their input. The resulting equilibrium outcome, even when voluntary agreement occurs, nevertheless generates lower than optimum payoffs, in the aggregate and for each of the individual actors.

Ironically, Heller explicitly cites the theoretical model, praising the version constructed by Buchanan and Yoon (2000) for demonstrating his anticommons hypothesis mathematically $(2008$, p. 21) and for showing analytically how his concept identifies a constant problem across disparate observations (2008, p. 42). He applauds the increasing sophistication of formal modeling for anticommons, footnoting the work of Schultz, Parisi and Depoorter (2002) and Parisi, Schulz \& Depoorter (2005) while commenting that game theory is "useful for parsing anticommons dynamics" (2008, n. 61 at p. 209; n. 44 at p. 213). Yet Heller does not seem to grasp the logical implications inherent to the model that he celebrates. On occasion, he writes of failed cooperation caused because property owners separately are pursuing the highest possible rental or sales price (2008, p. 146), but he never distinguishes this version of bundling inefficiency from dissimilar versions arising from such factors as personal resentments, actor irrationality, transaction costs, imperfect information, or decision-making complexity. Moreover, Heller is so focused on complete bargaining collapse that he overlooks a major implication of the underlying model, that consensual multiple player agreements also will most likely lead to suboptimal outcomes. It is certainly true that mutual intransigence by self-interested actors in pursuit of the maximum return, each possessing the power of exclusion, can result in imposed conditions so onerous that successful bundling becomes infeasible. Anticommons, however, does not require such an extreme outcome. Equilibrium calculations from the model predict that bundling cooperation will generally occur among rational actors, but at a location of systematic underutilization.

As an aside, we also note that Ronald Coase was not correct when he asserted, given rational and costless transactions, that the negotiated outcome will always lead to the Pareto efficient use of resources. Anticommons provides a direct counter-example (Major, King \& Marian, 2016). It is not merely that multiple owners complicate transactions, or even that they have extra incentive to exaggerate costs and provide misleading information. Rather, the logic of anticommons maximization itself entails equilibrium at a suboptimal location relative to what would have occurred had the property right been unified. Each rational actor will pursue a Nash strategy, protecting herself against aggressive play from others and insuring the highest possible gain regardless of the positions the others adopt. Each ideally will calculate the first-order condition of rent maximization in which the first derivative of her payoff by her price, contingent upon the prices charged by the other players, is set at zero since she wishes it to be invariant regardless of what the other players choose to do. When all players act with strategic rationality and without constraint, the combined outcome is suboptimal relative to the alternative case based on an altruistic cartel of cooperative players. By implication, the rational tragedy of the anticommons has important theoretical political-economic significance.

Michael Heller's analytic imprecision, yet again, leads to conceptual confusion. Returning to the example of a biomedical innovation requiring multiple patents, there are many reasons why bundling might fail to occur or 
would occur at a remarkably inferior price/quantity combination. Most do not require rigorous analysis. There are, for instance, situations of transition (Lametti, 2013), when the powers conveyed by property rights are uncertain, legal enforcement is unavailable, credit and financing are underdeveloped, and economic markets are in flux. There is an obvious distinction between necessary approvals that fail to occur due to the systematic factors inherent to the choice situation and those due to conditions of temporary puzzlement and ad hoc adjustments largely resolved with the passage of time. Similarly, bundling can fail because of non-decisions (for example, insufficient information to identify the relevant patent holders), because of an inability to make decisions (for example, breakdowns in communication among the relevant patent holders), or because of conscious negative decisions (for example, the choice not to sell a patent to a given pharmaceutical company that has a history of over-charging customers or neglecting environmental protections). Permissions, moreover, sometimes fail to be assembled as a consequence of ordinary organizational bumbling and stumbling. Bureaucratic inefficiency and intransigence are commonplace occurrences and do not require any new conceptual addition to the academic repertoire.

Our recommendation is to restrict the anticommons concept, keeping it distinct from the more familiar causes that limit bundling success. The object is to add specificity to the existing literature and to isolate this particular strategic tragedy. Situations entailing separate yet complementary inputs need not all be analyzed in the same way; not all of them are equally theoretically interesting and policy relevant. Anticommons is a subset within this domain. The failure that it identifies is strategic rather than transactional. Each patent-holder pursues the maximum feasible gain for awarding license permission while recognizing simultaneously that her return is interdependent upon the separate prices imposed by autonomous other patent-holders. Anticommons deserves special significance because the collectively produced equilibrium is not merely unfortunate but tragic, resulting in inefficient utilization even when the actors are rational and aware that their maximizing behavior achieves an inferior outcome.

From this perspective, in order for the strategic anticommons situation to proceed, it is required that the relevant autonomous actors know that they have control over a necessary input, and they also must have common knowledge (I know, and you know that I know, and I know that you know that I know, etc. (Aumann, 1976; Chwe, 2001)) that there are other inputs necessary for the decision to be made or the product created. The players therefore reciprocally comprehend that they are in parallel circumstances, that all have powers of exclusion to deny bundling and that each is free to exercise that power. It is a condition that effectively excludes from the anticommons registry all cases of failed bundling caused by legal confusion, uncertainty, and misrepresentation; by temporary adjustment to new circumstances; and by ordinary bureaucratic inefficiency.

Second, the actors in an anticommons situation must know, and mutually know that they know, that the combination of use permissions will produce an outcome generating net benefit above cost. This requirement places anticommons within the family of potential positive externalities, generating rents that are available for allocation upon successful bundling of the separate consents. This requirement excludes from the anticommons registry the situation in which Mary rejects John's proposal of marriage because she does not love him, as well as all other cases (such as homeowners bluntly refusing to move for the construction of a new airport runway, or bandwidth holders refusing to cede space for new entrants, or patent holders refusing to sell licenses to unscrupulous manufacturers, or regulators rejecting permission for an unwarranted development project) where one or more among the necessary 'owners' of an input does not believe that any positive value will be gained individually from her consent to a bundled agreement.

Finally, the actors must all know, and mutually know that they know, that the payoffs available are variable. For any fixed social return from bundling, the share to a given player is undetermined. Toward the lower extreme, the player would most likely refuse consent; toward the upper extreme, the other players most likely would refuse consent. Yet there is ample room for calculated play in between. Similarly, the entire social return is variable. At the extreme, the sum of the prices charged to the bundler for purchasing the necessary consents might make the total project no longer worthwhile. But, short of that extreme, higher than optimum prices upon the bundler can result in lower quantities supplied and thus lower total returns available to be allocated. Thus the players collectively know that they are involved in a complex strategic game. While they might all seek to obtain the largest possible share of the positive surplus, the best response is to adopt a position in recognition of the probable positions adopted by the others who equally possess exclusion rights. The prediction, nonetheless, in situations of multiple separate sellers with necessary and complementary inputs, is that the combined result will be Pareto suboptimal.

The anticipated reply is that there is no need to enforce such a strict conceptual division; anticommons can be utilized across a range of possible motivations; regardless of the particulars, all entail fragmentation of the right 
to exclude from use, resulting in property underutilization. If so, anticommons ostensibly could admit applications logically independent of strategic maximization, caused for example by the practical difficulties in identifying and coordinating separated actors or by individual refusals to contemplate bargains or by the institutional complexity of the bargaining situation. Yet there is no real gain from employing anticommons in this broader sense. There might be empirical interest to discover whether, in a particular field, negotiating imperfections introduce significant barriers to valuable bundled agreements. There is, however, no theoretical advantage from awarding anticommons multiple meanings. There already exist elaborate literatures discussing transaction costs, institutional impediments, and the psychological biases that favor one's initial endowments. There is a fine literature on asymmetric holdup, in which one or more players temporarily delay necessary agreement with the intent to extract rents greater than reservation price (Cohen, 1991; Epstein, 1993). The only realization contributed by Heller's undifferentiated inclusiveness is the claim, useful but not quite surprising, that bundling complications occur often in negotiations and become ever more difficult as the quantity of essential parties increases. On the other hand, there is great cost in failing to distinguish among dissimilar causes and competing explanatory frameworks. Far more originality and precision lies with the narrower meaning of anticommons based on non-cooperative game theory and self-interested maximizing play. As Hahnel and Sheeran argue, in another context, any approach that reduces multiple-player bargaining inefficiencies merely to transaction costs "is misleading because it trivializes problems created by perverse incentives and underplays their importance" (2009, p. 229).

Allowing conceptually for anticommons tragedy to arise from all sorts of situational imperfections is misleading in another sense, for it destroys strict symmetry with the more familiar tragedy of the commons. Heller places much emphasis on this symmetry, drawing a so-called "spectrum of ownership" with ordinary private property in the middle, flanked to one side by commons property and to the other by anticommons property $(2008$, p. 18). It suggests a continuum from too little privatization to too much privatization, from over-utilization to under-utilization of a scarce resource. Importantly, the tragedy of the commons is a rational tragedy, and Heller seems to acknowledge it. "The most intractable overuse tragedy," he writes about the commons, "arises when individuals choose rationally to consume a scarce resource even though each knows that the sum of these decisions destroys the resource for all" $(2008$, p. $16 ; 2013$, p. 8). Thus there is an odd contradiction between his discussion of the commons and his explanation of the anticommons. If symmetry is sought, both must be established on reciprocal logics.

In the commons, there is a collective property that each player can use unilaterally but none can prevent others from using. In the anticommons, there is a collective property that no player can use unilaterally but each can prevent others from using. Both rest upon non-cooperative games among separated actors. Ironically, if all players adopt a strategy of altruism, all will benefit, yet any player who unilaterally adopts a strategy of altruism will as a consequence realize a lower return. There is a rational maximizing strategy for each player but the combination of those strategies is still inescapably tragic - leading to systematic over-demand (commons) or systematic over-pricing (anticommons). Parallel treatment of the two reciprocal rational tragedies mandates that the concept of anticommons be constituted rigorously, denying Heller's encompassing usage.

The conclusion, yet again, is that there is substantial confusion regarding anticommons, affecting the meaning of the concept and the construction of cases covered. The implication is that some of the most popular illustrations of anticommons found in the literature might not be. Our objective is not to dismiss the concept, but instead to demonstrate the need for much greater clarity and specificity in its definition, thereby highlighting its special contribution to the law-and-economics literature.

To the extent that Heller's point is merely that fragmented property rights can have undesirable social consequences when efficient bundling does not occur, we have no disagreement. It remains an empirical question when this occurs and how severe the social cost. To the extent that Heller goes further, however, claiming that there is a unifying concept relevant across all situations of property fragmentation with adverse consequences, we strongly disagree. Our recommendation is to constrain the operationalization of anticommons consistent with the interpretation reflected in the underlying model from non-cooperative game theory - founded on (a) multiple, separated players controlling complementary inputs to a valued product and (b) their strategic maximizing behavior regarding the prospective positive return from any successful bundling of use permissions, emphasizing how players position against each other as well as against the actor who wishes to obtain their necessary inputs. There will remain ample real-world anticommons applications, with implications for how society best constructs economic, social, and political relationships. 


\section{Applications of the Anticommons Logic}

The object of this final section is briefly to suggest the empirical plausibility of the strategic understanding of anticommons tragedy and to indicate the kind of story necessary for a viable application. Despite our specifications regarding the nature and domain of the concept, there remain many appropriate illustrations, both substantively rich and theoretically significant.

Evidence regarding plausibility comes in part from controlled laboratory experiments. In some, the 'owners' of necessary inputs autonomously are selecting prices that together affect the quantity of commodities purchased (Steward \& Bjornstad, 2002). In others, the 'owners' are selecting prices that together affect the probability of purchase for a unified, single commodity (Vanneste, Van Heil, Parisi \& Depoorter, 2006; Depoorter \& Vanneste, 2007). Across these experiments, the strategic dilemma is the same. If the players collectively set their reservation prices too high, the buyer will not purchase enough of their parcels or possibly not purchase them at all, limiting the available return. Yet each single owner, if she sets her reservation price too low, risks once the parcels are assembled sacrificing potential gain to the others. Across all these tests, the anticommons hypothesis was sustained. The separated players proved far too aggressive in their pricing, with the consequence that potential value remained unrealized, both socially and individually. This remained true even when the sellers had full knowledge that a higher sum price would drastically reduce the quantity or probability of purchase. It remained true, moreover, even when the sellers knew the amount of the potential surplus lost given different levels of deviation from efficient bundling.

A laboratory setting with volunteer respondents is helpful for insuring player awareness of the underlying game structure and for minimizing the impact of extraneous factors (Ostrom, Gardner \& Walker, 1994). Outcome suboptimality across repeated trials can thus be reasonably attributed to strategic behavior consistent with the anticommons model. Yet the laboratory is a special venue, raising issues regarding external validity. Analysis of anticommons applications occurring naturally in the 'real world' is more complicated, requiring a discussion beyond what can be accommodated in the remainder of this paper. Instead, we will provide just two illustrative stories, selected intentionally to reside in academic fields quite distant from ordinary economic markets in order to demonstrate the breadth and importance of the rigorously defined anticommons concept.

Imagine three institutionally separate primary schools that agree to stage a holiday festival for the students and their parents. The three schools together can produce a far better festival than any single one of them can do alone. Even further, the three together can produce a better festival, with higher net utility, than the sum of three separate festivals. This is because of combination effects, the elimination of redundant expenditures, and efficiencies of scale. This is an anticommons situation - there is a positive externality to be realized from cooperation, dependent on the consent of all three; each separate school nevertheless calculates its own maximizing cost/benefit position.

Any one of the schools might decline to participate. The principals might dislike each other or there could be a long history of cross-school rivalry. There might be coordination problems, in which the schools fail to secure sufficient assurances that the others truly will participate. There might be transaction problems resulting in miscommunication or mis-coordination. Yet none of these potential barriers are especially challenging, theoretically or empirically. In fact, schools that foresee the disappearance of valued external benefits have an extra incentive to inspire added confidence or reduce transaction costs. Whether this happens or not is simply a practical matter.

A much more serious problem comes from the fact that the schools calculate individually. For any given size cooperative festival, each knows that it can improve its net utility by shifting some of the burden of participation onto the others. "We would love to participate but lack adequate funds," School S might insist, "so we need others to pay for the bus to bring our students or for more of the refreshments"; or "we are constrained and can offer fewer activities, so the other schools will have to participate disproportionately more." The net gain from the festival would be the same, but the cost to School S would be lower, improving its anticipated return. Given that all three schools rationally will propose similarly, the result is a non-cooperative game for which there is a maximizing strategy. The Nash 'best response' entails that each school recognizes the strategic interests of the others, selecting for itself the option that makes it indifferent across the options the others might select. When all the schools do this, there is an equilibrium solution and voluntary cooperation will occur. The problem is that the Nash equilibrium entails lower contributions from each of the schools, resulting in a smaller and less satisfying festival than is optimal and potentially achievable.

Imagine instead the three schools existing under a governing authority that requires cooperation and assigns them tasks. The authority might allocate so that each school does one-third. It might recognize that schools have 
different cost structures or different abilities to contribute, and it might allocate tasks to reflect this. The essential point is that the three schools deciding rationally yet separately regarding their collective project will select lower contributions than the central authority would assign. It is not just that the festival would be larger and better with greater contributions from all the schools; the festival would be proportionately better. For each unit of contribution, there would be greater than one unit of gain in the net impact, but this will not be achieved. Even further, the inefficiency is not only at the aggregate level. Each of the participating schools would benefit more than proportionally had all their contributions been larger, but no school will do so. Because each calculates its most beneficial extent of participation independently, and because the total return in part depends on the self-interested contributions from others, and because each does not value the share of the return realized by others, and because none cannot control the behavior of the others - each will play a Nash best-response strategy, resulting in a rational tragedy of Pareto inefficient underutilization.

This example is, in fact, not purely hypothetical. Something quite similar occurred in Romania in 2012 upon the introduction of a new "Grade Zero" into the primary school system, when approximately 12,000 children were left without proper places after a tug-of-war over costs despite broad consensus among all the relevant government agencies that the successful creation of a Grade Zero would better help educate the nation's children. Similarly, it occurred regarding merger negotiations for certain of Romania's universities, which saw incomplete success despite the visible prospect of higher international rankings and reduced administrative costs for all the participants (Marian, 2013). The same logic, moreover, applies to situations involving multiple nations who must cooperate to achieve a collective goal. Anticommons has thus been used to explain, for instance, the weakness of successive bailout programs for the Greek debt crisis based on the uncoordinated and competitive strategies of the Eurozone countries (Major, 2014).

The three-schools anticommons story emerges from strategic behavior regarding control over quantity. The identical tragic result can occur from strategic behavior over price. Imagine three bureaucratic agencies each of which must give approval for a socially valuable project to proceed. For instance, one bureaucracy might be responsible for certifying fair employment practices, one for insuring environmental compliance, and one for supervising occupational safety. Every delay, according to program advocates, raises the cost of the project and reduces its social value, as does each additional restriction imposed on program operations. Yet the separate bureaucratic agencies also have a public function, which they understand is necessary despite the price imposed on the net return.

There is a maximizing price-quantity combination. The anticommons hypothesis asserts that a unified bureaucratic agency that incorporates all three regulatory functions will find it. Three separate agencies, each with its own autonomous obligations, will not. This is not because of bureaucratic intransigence or incompetence or inefficiency. Rather, over-pricing will occur from strategic rationality, and deadweight loss results from concurrent possession of rights to exclude. In anticommons, the multiple separate holders of exclusion rights do not fully internalize the costs created by the enforcement of such rights as they bear upon the calculations of the others. The quantity supplied is a function of the sum of prices charged, $P_{1}+P_{2}+P_{3}$. Yet each agency sets its price independently of the others, and each strategically will set its price too high.

Assume that each agency knows the optimal price-quantity combination, which will maximize the social value of the project given the conjoint need to insure fair employment, environmental protection, and occupational safety. Yet each also knows that, given separate decision-makers, it cannot enforce that optimizing position by itself, and each believes self-interestedly in its own individual bureaucratic mission. Whatever the optimizing price, $P^{*}$, each agency will seek to advance its own regulatory agenda relative to the others, thus raising its share of the price for the overall project. The others might voluntarily yield and lower their prices, but probably not. Recognizing their parallel situations with common knowledge, according to the anticommons hypothesis, each agency has the incentive to calculate and play a Nash best-response strategy. There is an equilibrium result, but it will occur at a higher net price/lower quantity location than had there been a unified 'monopolist' agency coordinating all three regulatory functions simultaneously. The aggregated social gain will be lower than optimal. Moreover, although each of the separate agencies will be dissatisfied with the result they collectively have produced, none unilaterally will shift behavior.

Again, the example is not purely hypothetical. It can be used to explain the bureaucratic failure famously described by Pressman and Wildavsky (1973). In the middle 1960s, the U.S. Economic Development Administration awarded more than $\$ 23$ million to Oakland, California for public works projects with minority employment opportunities. Three years later, only about $\$ 3$ million had been spent and few jobs were created. The problem identified was the existence multiple agencies sitting at different levels of government with fragmented responsibilities yet combined jurisdiction, often entailing simultaneous clearances and replicated 
negotiations as conditions changed.

A soccer team has eleven players all of whom know that that they can anticipate improved chances of winning if they successfully coordinate together. Yet each player also knows that full coordination might mean some reduction in his own, individual-level measured statistics, which can affect fame, lucrative endorsements, and the size of any future contract. And each knows that all other players calculate similarly. Separate yet maximizing players will achieve some high level of athletic coordination but, according to the anticommons model, it will occur to a lower degree than optimal, resulting in somewhat fewer team wins. It is not surprising, therefore, that soccer squads hire managers, or that symphony orchestras all utilize conductors.

\section{Conclusion}

The question, Alice wondered in Through the Looking Glass, is why words can mean so many different things. "The question," Humpty Dumpty replied, "is which is to be the master - that's all" (Carroll, 1960, p. 213). This paper is intended to show that the concept of anticommons requires more rigorous specification than is ordinarily found in the existing literature. Definition in terms of fragmented legal ownership over a joint property has often been considerably stretched and more plausibly should be replaced by the notion of separate yet necessarily complementary inputs. The underlying motivation for the failure of optimal bundling has often been left vague and encompassing, neglecting important analytic distinctions. Reliance upon misperception, intransigence, or bargaining complications ignores the fact that inefficiency can actually occur from the intentional maximizing behavior of fully rational actors with perfect information under ideal bargaining conditions.

Anticommons, in our opinion, should be restricted to situations of conscious strategic play over the creation and allocation of a potential positive externality resulting from agreement across separated actors all of whom possess powers of use exclusion over a necessary component. The failure to achieve efficient bundling among the fragments thus emerges as a systematic rather than accidental outcome. Nevertheless, anticommons remains an important contribution to social and economic analysis. Our object has been to help insure that contribution, reinforcing attention to the inherent strategic logic that gives the concept both novel theoretical insight and significant explanatory power.

\section{Acknowledgments}

The authors would like to express their thanks the Bruce E. Porteous Endowment for its generous support, and to Lee Anne Fennell, Daniel Pop, the General Education Sub-Board of the Open Society Foundation, and the anonymous referees for their comments and recommendations.

\section{References}

Aumann, R. J. (1976). Agreeing to Disagree. The Annals of Statistics, 4, 1236-1239. http://dx.doi.org/10.1214/aos/1176343654

Blackstone, W. (1765-69). On Property in General. In W. Blackstone, Commentaries on the Laws of England. Book 2, Chapter 1. Retrieved July 25, 2013, from http://www.lonang.com/exlibris/blackstone/bla-201.htm

Buchanan, J. M., \& Yoon, Y. J. (2000). Symmetric Tragedies: Commons and Anticommons. The Journal of Law and Economics, 43, 1-14. http://dx.doi.org/10.1086/467445

Carroll, L. (1960). The Annotated Alice. New York, NY: W.W. Norton.

Chwe, M. S-Y. (2001). Rational Ritual. Princeton, NJ: Princeton University Press.

Coase, R. H. (1960). The Problem of Social Cost. Journal of Law and Economics, 3, 1-44. http://dx.doi.org/10.1086/466560

Coase, R. H. (1988). Notes on the Problem of Social Cost. In R. H. Coase (Ed.), The Firm, The Market, and the Law (pp. 157-185). Chicago, IL: University of Chicago Press.

Cohen, L. (1991). Holdouts and Free Riders. Journal of Legal Studies, 20, 351-62. http://dx.doi.org/10.1086/467890

de Saussure, F. (1959). Course in General Linguistics (W. Baskin, Trans.). New York, NY: Philosophical Library.

Depoorter, B., \& Vanneste, S. (2006). Putting Humpty Dumpty Back Together: Pricing in Anticommons Property Arrangements. Journal of Law, Economics, and Public Policy, 3, 1-28.

Epstein, R. A. (1993). Holdouts, Externalities, and the Single Owner: One More Salute to Ronald Coase. Journal of Law and Economics, 36, 553-86. http://dx.doi.org/10.1086/467289

Epstein, R. A., \& Kuhlik, B. N. (2004). Is There a Biomedical Anticommons? Regulation, 27, 54-58. 
Fennell, L. A. (2004). Common Interest Tragedies. Northwestern University Law Review, 98, 907-990.

Fennell, L. A. (2011). Commons, anticommons, semicommons. In K. Ayotte, \& H. E. Smith (Eds.), Research Handbook on the Economics of Property Law (pp. 35-56). Cheltenham UK: Edward Elgar. http://dx.doi.org/10.4337/9781849808972.00007

Hahnel, R., \& Sheeran, K. A. (2009). Misinterpreting the Coase Theorem. Journal of Economic Issues, 43, 215-237. http://dx.doi.org/10.2753/JEI0021-3624430110

Hansen, S., Brewster A., Asher J., \& Kisielewski, M. (2006). The Effects of Patenting in the AAAS Scientific Community. Washington DC: American Association for the Advancement of Science.

Heller, M. A. (1998). The Tragedy of the Anticommons: Property in the Transition from Marx to Markets. Harvard Law Review, 111, 621-88. http://dx.doi.org/10.2307/1342203

Heller, M. A. (1999). The Boundaries of Private Property. The Yale Law Journal, 108, 1163-1223. http://dx.doi.org/10.2307/797326

Heller, M. A. (2008). Gridlock Economy. New York, NY: Basic Books.

Heller, M. A. (2013). The Tragedy of the Anticommons: A Concise Introduction and Lexicon. The Modern Law Review, 76, 6-25. http://dx.doi.org/10.1111/1468-2230.12000

Heller, M. A., \& Eistenberg R. S. (1998). Can Patents Deter Innovation? The Anticommons in Biomedical Research. Science, 280, 698-701. http://dx.doi.org/10.1126/science.280.5364.698

Hohfeld, W. N. (1919). Fundamental Legal Conceptions As Applied to Judicial Reasoning. New Haven, CT: Yale University Press.

Honoré, A. M. (1961). Ownership. In A.G. Guest (Ed.), Oxford Essays in Jurisprudence (pp. 107-147). Oxford UK: Oxford University Press.

Kitch, E. W. (2003). Comment on the Tragedy of the Anticommons in Biomedical Research. In F. S. Kieff (Ed.), Perspectives on Properties of the Human Genome Project (pp. 271-273). London: Elsevier. http://dx.doi.org/10.1016/s0065-2660(03)50013-x

Lametti, D. (2013). The Concept of the Anticommons: Useful, or Ubiquitous and Unnecessary? In H. Howe (Ed.). Concepts of Property in Intellectual Property Law (pp. 232-257). Cambridge UK: Cambridge University Press. http://dx.doi.org/10.1017/CBO9781107300880.013

Major, I. (2014). A Political Economy Application of the 'Tragedy of the Anticommons': The Greek Government Debt Crisis. International Advances in Economic Research, 20, 425-37. http://dx.doi.org/10.1007/s11294-014-9494-8

Major, I., King, R. F., \& Marian, C. G. (2016). Anticommons, the Coase Theorem, and the Problem of Bundling Inefficiency. International Journal of the Commons, 10, 244-264. http://dx.doi.org/10.18352/ijc.614

Marian, C. G. (2013). Education in the Anticommons: Evidence from Romania. Report presented to the Open Society Foundation - General Education Sub-Board. New York, NY.

Maurer, S. M. (2006). Inside the Anticommons: Academic scientists' struggle to build a commercially self-supporting human mutations database, 1999-2001. Research Policy, 35, 839-853. http://dx.doi.org/10.1016/j.respol.2006.04.008

Max Levine Ensemble. (2010). Tragedy of the Anti-Commons. Retrieved November 25, 2013, from http://www.plyrics.com/lyrics/maxlevineensemble/tragedyoftheanticommons.html

Murray, F., \& Stern, S. (2007). Do formal intellectual property rights hinder the free flow of scientific knowledge? An empirical test of the anti-commons hypothesis. Journal of Economic Behavior and Organization, 63, 648-687. http://dx.doi.org/10.1016/j.jebo.2006.05.017

Ostrom, E., Gardner, R., \& Walker, J. (1994). Rules, Games, and Common-Pool Resources. Ann Arbor, MI: University of Michigan Press.

Parisi, F., Schultz N., \& Depoorter B. (2004). Simultaneous and Sequential Anticommons. European Journal of Economics, 17, 175-90. http://dx.doi.org/10.1023/B:EJLE.0000014575.00312.15

Parisi, F., Schultz, N., \& Depoorter, B. (2005). Duality in Property: Commons and Anticommons. International Review of Law and Economics, 25, 578-591. http://dx.doi.org/10.1016/j.irle.2005.12.003

Park, J. Y. (2010). The Tragedy of the Microarray Anticommons. Clinical Chemistry, 56, 1683-1685. 
http://dx.doi.org/10.1373/clinchem.2010.154740

Pressman, J. L., \& Wildavsky A. (1973). Implementation. Berkeley, CA: University of California Press.

Schulz, N., Parisi, F., \& Depoorter, B. (2002). Fragmentation in Property: Towards a General Model. Journal of Institutional and Theoretical Economics, 158, 594-613. http://dx.doi.org/10.1628/0932456022975196

Shapiro, C. (2001). Navigating the Patent Thicket: Cross Licenses, Patent Pools, and Standard Setting. In A. B. Jaffe, J. Lerner, \& S. Stern (Eds.), Innovation Policy and the Economy (Vol. I., pp. 119-150). Cambridge, MA: National Bureau of Economic Research/MIT Press. http://dx.doi.org/10.2139/ssrn.273550

Stewart, S., \& Bjornstad D. J. (2002). An Experimental Investigation of Predictions and Symmetries in the Tragedies of the Commons and Anticommons. Joint Institute for Energy \& Environment, Report No. JIEE 2002-07. Retrieved March 18, 2013, from http://isse.utk.edu/pdf/jieepubs/2002_07Experiment.pdf

Vanneste, S., Van Heil, A., Parisi, F., \& Depoorter, B. (2006). From 'tragedy' to 'disaster': Welfare effects of commons and anticommons dilemmas. International Review of Law and Economics, 26, 104-122. http://dx.doi.org/10.1016/j.irle.2006.05.008

Walsh, J. P., Arora, A., \& Cohen, W. M. (2003). Working Through the Patent Problem. Science, 299, 1021. http://dx.doi.org/10.1126/science.299.5609.1021

Walsh, J. P., Cho, C., \& Cohen, W. M. (2005). View from the Bench: Patents and Material Transfers. Science, 309, 2002-3.

Yuan, Y. (2009). Tragedy of Anti-Commons, Empirical Evidence from the Pharmaceutical Industry. Retrieved September 23, 2013, from http://extranet.isnie.org/uploads/isnie2009/yuan.pdf

Ziedonis, R. H. (2004). Don't Fence Me In: Fragmented Markets for Technology and the Patent Acquisition Strategies of Firms. Management Science, 50, 804-820. http://dx.doi.org/10.1287/mnsc.1040.0208

\section{Copyrights}

Copyright for this article is retained by the author(s), with first publication rights granted to the journal.

This is an open-access article distributed under the terms and conditions of the Creative Commons Attribution license (http://creativecommons.org/licenses/by/4.0/). 